\title{
Preoperative $\beta$-blocker use correlates with worse outcomes in patients undergoing aortic valve replacement
}

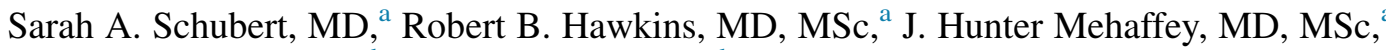
Clifford E. Fonner, BA, ${ }^{b}$ Jeffery B. Rich, MD, ${ }^{b}$ Alan M. Speir, MD, ${ }^{\mathrm{c}}$ Mohammed Quader, MD, ${ }^{\mathrm{d}}$ Irving L. Kron, $\mathrm{MD},{ }^{\mathrm{a}}$ Leora T. Yarboro, $\mathrm{MD},{ }^{\mathrm{a}}$ and Gorav Ailawadi, $\mathrm{MD}^{\mathrm{a}}$

\section{ABSTRACT}

Objectives: $\beta$-Blocker use is associated with fewer cardiac complications in patients undergoing noncardiac surgery and is a quality metric for coronary artery bypass grafting. We sought to determine the influence of preoperative $\beta$-blocker administration before aortic valve replacement (AVR).

Methods: All patients undergoing isolated AVR from 2002 to 2016 were extracted from a multi-institutional, statewide database composed of Society of Thoracic Surgeons data. Patients were propensity score matched by preoperative and operative variables, and the effects of preoperative $\beta$-blockers on outcomes were assessed.

Results: Of 7380 eligible patients, 53\% received a preoperative $\beta$-blocker. After propensity matching, a total of 4592 patients were well matched (1:1) with minimal baseline differences between groups. Within the matched cohort, the operative mortality rate ( $\beta$-blocker: $2.8 \%$ vs no $\beta$-blocker: $2.4 \% ; P=.454$ ) and rate of major morbidity $(14.4 \%$ vs $12.7 \% ; P=.101)$ were similar between groups. The rates of cardiac arrest $(2.1 \%$ vs $1.3 \% ; P=.034)$, renal failure requiring dialysis $(1.7 \%$ vs $0.9 \% ; P=.007)$, and postoperative transfusion $(38.2 \%$ vs $33.8 \% ; P=.002)$ after AVR were significantly greater in the cohort receiving preoperative $\beta$-blockade. Postoperative atrial fibrillation was also more prevalent in patients receiving a preoperative $\beta$-blocker $(26.9 \%$ vs $23.4 \% ; P=.007)$. Finally, preoperative $\beta$-blocker use was associated with longer postoperative intensive care unit stays (45.2 vs 47.0 hours; $P=.001$ ), but clinically similar hospital length of stay.

Conclusions: Preoperative $\beta$-blocker administration is not associated with improved outcomes after AVR but instead is associated with increased postoperative morbidity. Routinely initiating preoperative $\beta$-blockade is not supported in patients undergoing AVR. (J Thorac Cardiovasc Surg 2019;158:1589-97)

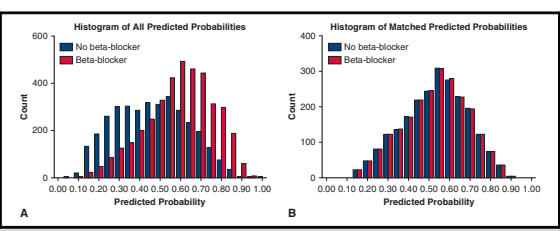

A propensity score match led to well-matched cohorts to study preoperative $\beta$-blockade.

Central Message

Preoperative $\beta$-blockade is associated with worse outcomes in patients undergoing aortic valve replacement, including increased postoperative atrial fibrillation, renal failure requiring dialysis, and transfusions.

\section{Perspective}

Given the significantly increased risks of postoperative cardiac arrest, atrial fibrillation, transfusion, and renal failure requiring dialysis for patients receiving a preoperative $\beta$-blocker medication, surgeons should consider each patient individually to determine whether a preoperative $\beta$-blocker medication should be continued and be cognizant of these risks before initiating a new $\beta$-blockade before aortic valve replacement.

See Commentaries on pages 1598 and 1600 .
From the a Division of Thoracic and Cardiovascular Surgery, University of Virginia, Charlottesville, Va; ${ }^{b}$ Virginia Cardiac Services Quality Initiative, Virginia Beach, Va; ${ }^{\mathrm{c} I n o v a}$ Heart and Vascular Institute, Falls Church, Va; and ${ }^{\mathrm{d}}$ Department of Cardiothoracic Surgery, Virginia Commonwealth University, Richmond, Va.

The National Heart, Lung, and Blood Institute of the National Institutes of Health under Award No. T32HL007849 supported research reported in this publication. The content is solely the responsibility of the authors and does not necessarily represent the official views of the National Institutes of Health

Read at the 97th Annual Meeting of The American Association for Thoracic Surgery, Boston, Massachusetts, April 29-May 3, 2017.

Received for publication May 8, 2017; revisions received Dec 17, 2018; accepted for publication Dec 20, 2018; available ahead of print March 28, 2019.

Address for reprints: Gorav Ailawadi, MD, Department of Thoracic and Cardiovascular Surgery, University of Virginia, 1215 Lee St, Box 800679, Charlottesville, VA 22908 (E-mail: gorav@ virginia.edu).

$0022-5223 / \$ 36.00$

Copyright (c) 2019 Published by Elsevier Inc. on behalf of The American Association for Thoracic Surgery

https://doi.org/10.1016/j.jtcvs.2018.12.108
The effects of preoperative $\beta$-blockade have been investigated in randomized controlled trials in noncardiac surgery patients and have led to decreased mortality in patients with known coronary artery disease. ${ }^{1-3}$ In patients undergoing coronary artery bypass grafting (CABG), a large, retrospective analysis from 2002 using the Society of Thoracic Surgeons (STS) adult cardiac surgery national

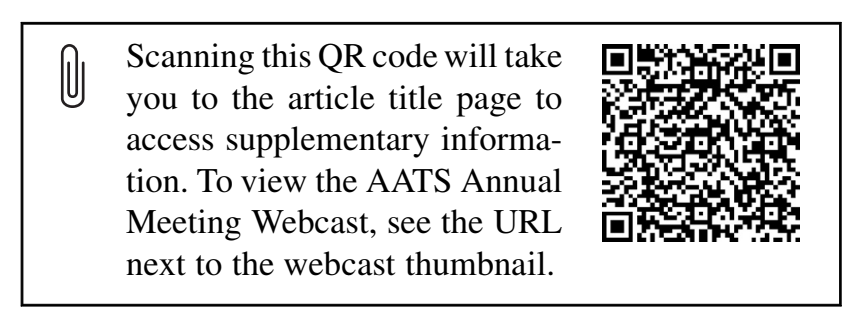




$$
\begin{aligned}
& \text { Abbreviations and Acronyms } \\
& \text { AVR = aortic valve replacement } \\
& \mathrm{CABG}=\text { coronary artery bypass grafting } \\
& \text { ICU = intensive care unit } \\
& \text { PRBC = packed red blood cells } \\
& \mathrm{PROM}=\text { predicted risk of mortality } \\
& \mathrm{PROMM}=\text { predicted risk of mortality and } \\
& \text { morbidity } \\
& \text { STS = Society of Thoracic Surgeons } \\
& \text { VCSQI = Virginia Cardiac Services Quality } \\
& \text { Initiative }
\end{aligned}
$$

performance and quality is essential. Given the questionable utility of preoperative $\beta$-blockade as a measure of quality care in patients undergoing $\mathrm{CABG}$, we hypothesized that preoperative $\beta$-blockade will not be associated with improved outcomes in patients undergoing AVR.

\section{METHODS \\ Data Acquisition}

The Virginia Cardiac Services Quality Initiative (VCSQI) is a voluntary collaboration of 18 cardiac surgical centers across the Commonwealth of Virginia from which a data registry has been constructed. The data are collected primarily for quality analysis and purposes outside of research. This study represents a secondary analysis of registry data with no Health Insurance Portability and Accountability Act patient-level identifiers and, as such, was exempt from review by the University of Virginia Institutional Review Board.

\section{Patient Selection and Outcomes}

De-identified patient data from January 2002 through June 2016 was obtained from the VCSQI database. Data were extracted for all patients who underwent nonemergency, isolated AVR for indications other than endocarditis. These patients were then stratified according to preoperative $\beta$-blocker administration. Patients' preoperative risk was determined from preexisting comorbidities and individually calculated STS predicted risk of mortality (PROM) score and predicted risk of mortality and morbidity (PROMM) score.

Outcomes reported were standard STS measures of morbidity and mortality, which included permanent stroke, cardiac arrest, renal failure, atrial fibrillation, prolonged ventilation, pneumonia, transfusions, readmission, discharge to a facility, and operative mortality. STS major morbidity was used as a composite measure of morbidity, and includes permanent stroke, prolonged ventilation, deep sternal wound infection, renal failure, and reoperation for any reason. Reoperation includes any patient who is taken back to the operating room for bleeding with or without tamponade, graft occlusion, valve dysfunction, or any other cardiac reason. Operative mortality is defined as within 30 days or before discharge.

\section{Statistical Analysis}

Categorical variables are presented as count $(\%)$ and continuous variables as median (quartile 1, quartile 3 ) because none were normally distributed according to the Kolmogorov-Smirnov test. Categorical variables were analyzed by $\chi^{2}$ test or Fisher exact test as indicated. Continuous variables were analyzed by Mann-Whitney $U$ test to account for skewness.

Patients were matched according to propensity to undergo preoperative $\beta$ blocker therapy. Using the same methodology as the STS, we first imputed missing values by using the lowest risk category for categorical variables, the gender-specific median for body surface area, and the median for ejection fraction. ${ }^{16}$ The propensity score was then calculated using multivariable logistic regression with stepwise variable selection. Variables included in the model are demonstrated in Table E1. Matching was performed in a 1:1 fashion using a greedy algorithm without replacement, specifically an 8 to 1 digit match. ${ }^{17}$ Balance among matched pairs was assessed by standardized mean differences and displayed in Figure E1. Among the matched cohort, paired univariate analyses were performed. All analyses were performed with SAS version 9.4 (SAS Institute Inc, Cary, NC).

\section{RESULTS}

\section{Patient Demographic and Operative Characteristics Before Matching}

Of 7380 patients who met study inclusion criteria, 53\% of patients received a preoperative $\beta$-blocker (Figure 1). 


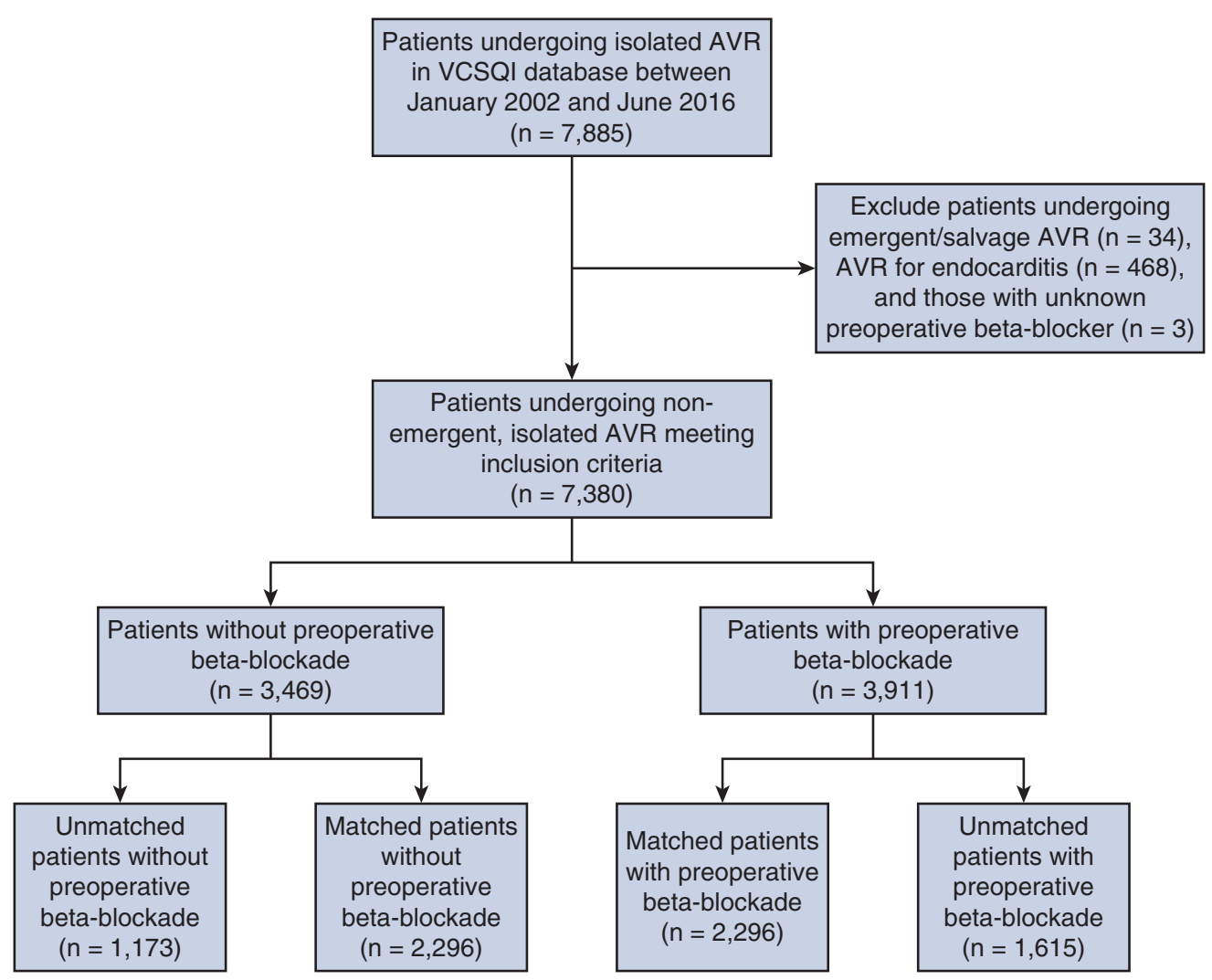

FIGURE 1. Consolidated Standards of Reporting Trials diagram detailing selection of patients within each cohort, including numbers of patients in each cohort before matching, after matching, and unmatched patients. AVR, Aortic valve replacement; VCSQI, Virginia Cardiac Services Quality Initiative.

Before matching, patients receiving a preoperative $\beta$-blocker were significantly older (70 vs 68 years; $P<.001)$ and had a higher prevalence of hypertension, coronary artery disease, recent congestive heart failure exacerbation, diabetes, and dialysis-dependent renal failure (Table E2). With these differences in baseline preoperative characteristics between the 2 groups, patients who received preoperative $\beta$-blockade had a greater STS PROMM $(15.8 \%$ vs $12.9 \% ; P<.001)$ and PROM $(2.3 \%$ vs $1.9 \% ; P<.001)$ (Table E2). Cardiopulmonary bypass time (median, 105 minutes; quartile 1, 86 minutes; quartile 3, 130 minutes versus median, 101 minutes; quartile 1,84 minutes; quartile 3,125 minutes; $P<.001$ ) was also significantly longer for those patients who were taking a preoperative $\beta$-blocker (Table E2).

\section{Preoperative Characteristics and Outcomes of Matched Patients}

After $1: 1$ propensity matching, a total of 4592 patients were well matched (Table 1 and Figure 2, $A$ and $B$ ). The patients in each cohort did not differ in age (median, 69 years; range, 60-77 years vs median 69 years; range, 60-77 years; $P=.310$ ) or any other preoperative variables, including rates of hypertension, anemia, coronary artery disease, preoperative atrial fibrillation, or heart failure (Table 1). There was good balance between groups for baseline characteristics with all standardized mean differences $<0.1$. There remained statistical differences in body mass index (29.1 vs 28.4; $P=.025)$ and whether or not patients were taking a lipidlowering medication before surgery $(56.6 \%$ vs $52.3 \%$; $P=.010)$ that are unlikely to be clinically meaningful. Patients' median STS PROM $(2.1 \%$ vs $2.1 \% ; P=.246)$ and STS PROMM ( $14.1 \%$ vs $13.7 \% ; P=.863)$ were not significantly different between the matched cohorts (Table 1). Cardiopulmonary bypass time (104 vs 100 minutes; $P=.0004)$ and crossclamp time (76 vs 73 minutes; $P=.0009)$ were significantly different between the cohorts, despite similar rates of annular enlargement between the cohorts $(4.2 \%$ vs $4.0 \% ; P=.764)$ (Table 1$)$.

\section{Outcomes in Matched Patients}

Operative mortality $(2.8 \%$ vs $2.4 \% ; P=.454)$ and STS major morbidity $(14.4 \%$ vs $12.7 \% ; P=.101)$ were similar between groups. The rate of cardiac arrest after AVR was significantly greater in the cohort receiving preoperative $\beta$-blockade $(2.1 \%$ vs $1.3 \% ; P=.034)$. More patients receiving a preoperative $\beta$-blocker required initiation of hemodialysis for renal failure $(1.7 \%$ vs $0.9 \% ; P=.007)$ following AVR. Transfusion of any blood products $(38.2 \%$ vs $33.8 \% ; P=.002)$ and transfusion of PRBCs 
TABLE 1. Demographic and preoperative characteristics and operative features of matched patient cohorts

\begin{tabular}{|c|c|c|c|}
\hline Characteristic & Preoperative $\beta$-blocker $(n=2296)$ & No preoperative $\beta$-blocker $(n=2296)$ & $P$ value \\
\hline Age (y) & $69(60,77)$ & $69(60,77)$ & .310 \\
\hline Body mass index & $29.1(25.1,33.4)$ & $28.4(24.9,32.9)$ & .025 \\
\hline Female & $932(40.6)$ & $962(41.9)$ & .366 \\
\hline Smoker & $719(31.3)$ & $684(29.8)$ & .258 \\
\hline Hypertension & $1799(78.4)$ & $1786(77.8)$ & .551 \\
\hline Diabetes & $682(29.7)$ & $666(29.0)$ & .588 \\
\hline Dialysis dependent renal failure & $48(2.1)$ & $32(1.4)$ & .070 \\
\hline Peripheral arterial disease & $208(9.1)$ & $205(8.9)$ & .879 \\
\hline Cerebrovascular disease & $334(14.6)$ & 309 (13.5) & .273 \\
\hline Prior cerebrovascular accident & $115(5.0)$ & $108(4.7)$ & .632 \\
\hline Moderate or severe chronic lung disease & $235(10.2)$ & $223(9.7)$ & .555 \\
\hline Coronary artery disease & $483(21.0)$ & 457 (19.9) & .300 \\
\hline Prior myocardial infarction & $200(8.7)$ & $184(8.0)$ & .360 \\
\hline Heart failure within $2 \mathrm{wk}$ & $943(41.1)$ & 939 (40.9) & .901 \\
\hline Ejection fraction $(\%)$ & $60(50,63)$ & $60(51,63)$ & .595 \\
\hline Preoperative ACEI/ARB & $659(28.7)$ & $658(28.7)$ & .973 \\
\hline Preoperative lipid-lowering medication & $1167(56.6)$ & $1067(52.3)$ & .010 \\
\hline Preoperative atrial fibrillation & $216(9.4)$ & $205(8.9)$ & .565 \\
\hline Moderate or severe aortic insufficiency & $633(27.6)$ & $615(26.8)$ & .560 \\
\hline Aortic stenosis & $2029(88.4)$ & $2030(88.4)$ & .963 \\
\hline Moderate of severe mitral insufficiency & $192(8.4)$ & $203(8.8)$ & .564 \\
\hline Mitral stenosis & $51(2.8)$ & $72(4.2)$ & .136 \\
\hline Moderate or severe tricuspid insufficiency & $93(4.7)$ & $109(5.5)$ & .403 \\
\hline Previous cardiac intervention & $528(23.0)$ & $501(21.8)$ & .291 \\
\hline Previous valve surgery & $125(5.4)$ & $118(5.1)$ & .641 \\
\hline Previous CABG & $209(9.1)$ & $184(8.0)$ & .171 \\
\hline Reoperative status & $324(14.1)$ & $298(13.0)$ & .242 \\
\hline STS PROMM (\%) & $14.1(10.4,19.9)$ & $13.7(10.2,19.5)$ & .863 \\
\hline STS PROM (\%) & $2.1(1.2,3.7)$ & $2.1(1.2,3.6)$ & .246 \\
\hline \multicolumn{4}{|l|}{ Operative features } \\
\hline CPB time (min) & $104(86,129)$ & $100(84,124)$ & $<.001$ \\
\hline Crossclamp time (min) & $76(61,95)$ & $73(59,91)$ & $<.001$ \\
\hline Annular enlargement & $96(4.2)$ & $92(4.0)$ & .764 \\
\hline
\end{tabular}

Values are presented as median (25th, 75th percentile) or n (\%). ACEI, Angiotensin-converting enzyme inhibitor; $A R B$, angiotensin II receptor blocker; $C A B G$, coronary artery bypass grafting; STS PROMM, Society of Thoracic Surgeons predicted risk of morbidity and mortality; STS PROM, Society of Thoracic Surgeons predicted risk of mortality; $C P B$, cardiopulmonary bypass.

$(30.6 \%$ vs $26.2 \% ; P=.001)$ were also more common in patients receiving preoperative $\beta$-blockers. Postoperative atrial fibrillation was also more prevalent in patients receiving a preoperative $\beta$-blocker $(26.9 \%$ vs $23.4 \%$; $P=$.007) (Table 2).

Patients within the matched cohort who were taking a preoperative $\beta$-blocker had longer postoperative intensive care unit (ICU) stays (median, 45.2 hours; quartile 1,
25.1 hours; quartile 3,74 hours vs median, 47 hours; quartile 1, 24; quartile 3, 72 hours; $P=.023$ ) and hospital length of stay (median, 6 hours; quartile 1, 5 days; quartile 3, 8 days vs median 6 days; quartile 1 , 4; quartile 3,8 days; $P=.016$ ) (Table 2). This longer length of ICU and hospital stay did not translate into higher total hospitalization costs (median, $\$ 32,253$; quartile $1, \$ 25,560$; quartile $3, \$ 43,631$ vs median, $\$ 32,746$; quartile $1, \$ 25,864$; quartile $3, \$ 42,524 ; P=.563$ ). 

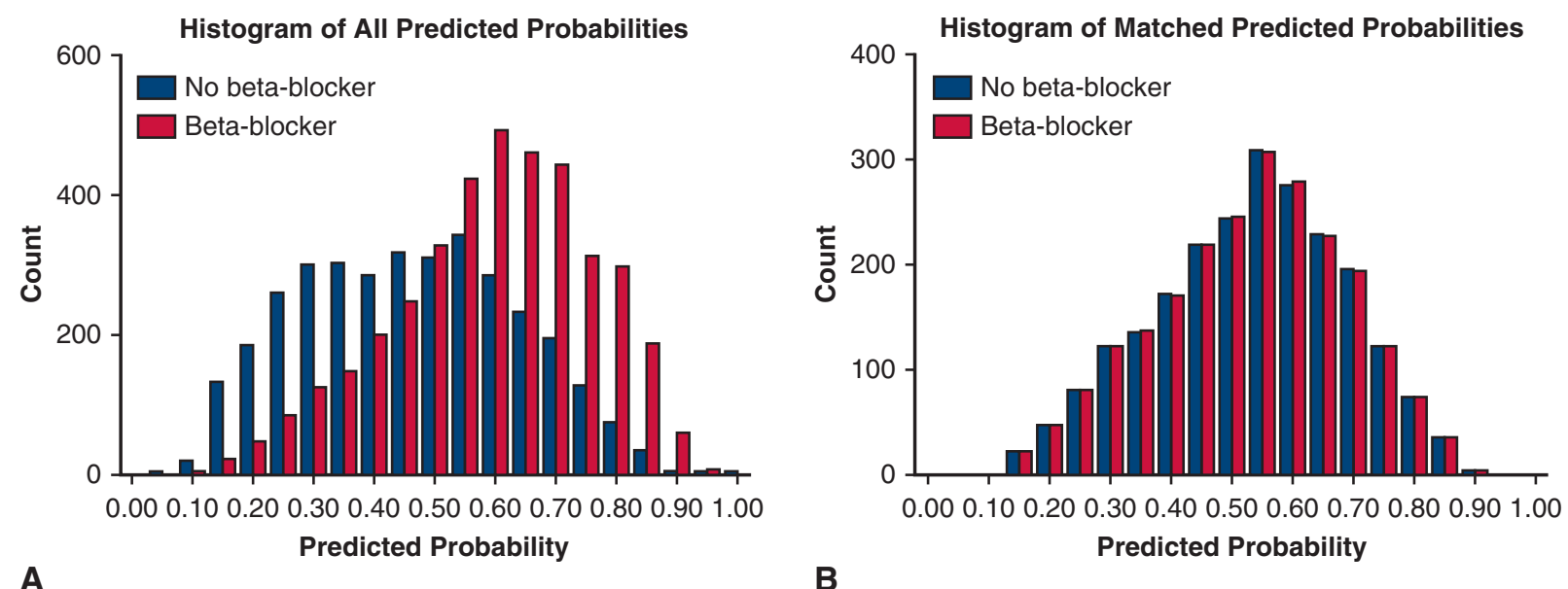

FIGURE 2. A, Preoperative characteristics varied widely between the 2 groups before matching. B, After matching, there were no significant differences between the matched cohorts. The blue bars represent patients who were not taking a preoperative $\beta$-blocker, whereas red bars represent those patients who were taking a preoperative $\beta$-blocker.

\section{DISCUSSION}

In this large cohort study of more than 4000 well-matched patients undergoing AVR across the state of Virginia, preoperative $\beta$-blocker use was associated with more frequent postoperative complications, specifically cardiac arrest, renal failure requiring hemodialysis, blood transfusions, and atrial fibrillation. In addition, patients who received a preoperative $\beta$-blocker experienced longer ICU stays and total hospitalization.

Preoperative $\beta$-blocker use in patients undergoing AVR was associated with significantly increased rates of postoperative cardiac arrest. Although cardiac arrest is a known complication of aortic stenosis-the most common pathology in this study population-the actual incidence

TABLE 2. Univariate analysis of patient outcomes within matched, paired groups as a function of preoperative $\beta$-blocker use in patients undergoing aortic valve replacement

\begin{tabular}{|c|c|c|c|}
\hline Outcomes & Preoperative $\beta$-blocker $(n=2296)$ & No preoperative $\beta$-blocker $(n=2296)$ & $P$ value \\
\hline STS operative mortality & $64(2.8)$ & $56(2.4)$ & .454 \\
\hline STS major morbidity* & $330(14.4)$ & $292(12.7)$ & .101 \\
\hline Permanent stroke & $33(1.4 \%)$ & $28(1.2 \%)$ & .515 \\
\hline Cardiac arrest & $47(2.1 \%)$ & $29(1.3 \%)$ & .034 \\
\hline Atrial fibrillation & $618(26.9)$ & $538(23.4)$ & .007 \\
\hline Pneumonia & $61(2.7)$ & $45(2.0)$ & .139 \\
\hline Prolonged ventilation & $195(8.5)$ & $176(7.7)$ & .299 \\
\hline Renal failure & $83(3.6)$ & $64(2.8)$ & .105 \\
\hline Renal failure requiring dialysis & $40(1.7)$ & $20(0.9)$ & .007 \\
\hline Deep sternal wound infection & $7(0.3)$ & $8(0.4)$ & .796 \\
\hline Any transfusion & $875(38.2)$ & $774(33.8)$ & .002 \\
\hline Transfusion of PRBC & $669(30.6)$ & $570(26.2)$ & .001 \\
\hline Reoperation for any reason & $11(4.8)$ & $98(4.3)$ & .391 \\
\hline Reoperation for bleeding & $84(3.7)$ & $73(3.2)$ & .361 \\
\hline 3-Day readmission & $236(10.5)$ & $216(9.8)$ & .511 \\
\hline Discharge to facility & $432(19.3)$ & $416(18.8)$ & .553 \\
\hline Total cost $(\$)$ & $32,253(25,560,43,631)$ & $32,746(25,864-42,524)$ & .563 \\
\hline ICU stay (h) & $45.2(25,74)$ & $42(24,72)$ & .023 \\
\hline $\operatorname{LOS}(d)$ & $6(5,8)$ & $6(4,8)$ & .016 \\
\hline
\end{tabular}

Values are presented as $\mathrm{n}(\%)$ or median (25th, 75th percentile). STS, Society of Thoracic Surgeons; $P R B C$, packed red blood cells; ICU, intensive care unit; $L O S$, length of stay.

*Includes permanent stroke, deep sternal wound infection, renal failure, prolonged ventilation, and reoperation for any reason. 
of this complication is relatively low. ${ }^{18}$ The results of this study suggest that preoperative $\beta$-blocker use does not protect against this complication after AVR.

Another significant morbidity found to be associated with preoperative $\beta$-blocker administration in this study is the development of renal failure requiring dialysis. $\beta$-Blockers act to blunt the normal physiologic sympathetic response to cardiac stress. ${ }^{19}$ When this physiology is inhibited, the myocardium may be unable to appropriately increase contractility and heart rate to maintain or increase cardiac output. Without the normal sympathetic response and subsequent increase in blood pressure, the renin-angiotensin system is activated, leading to vasoconstriction within the glomerular system and fall in the glomerular filtration rate, which, if allowed to persist, leads to reduced renal perfusion and eventual structural tubular damage. ${ }^{20}$ Although chronic stimulation of the adrenergic system-such as that which occurs with chronic heart failure-is detrimental, short-term adrenergic stimulation is a necessary mechanism to adequately support cardiac output and blood pressure in instances of (surgically induced) cardiac stress. ${ }^{21}$ Because $\beta$-blockers blunt this normal sympathetic response, hypoperfusion - particularly of the kidneys-persists both intraoperatively and postoperatively leading to the significant acute kidney injury demonstrated in this study.

Similar to what was previously reported in patients undergoing isolated $\mathrm{CABG}$, transfusions of any blood products, as well as transfusions of packed red blood cells (PRBCs), were significantly increased in valve patients with preoperative $\beta$-blockade. We suspect this may occur through similar mechanisms of blunted sympathetic output, and thus decreased physiologic vasoconstriction. ${ }^{22}$ Aside from increasing resource utilization, PRBC transfusions significantly increase short- and long-term mortality in patients undergoing cardiac surgery. ${ }^{23,24}$ Given the substantial implications of PRBC transfusions in patients undergoing cardiac surgery, the increased rate of PRBC transfusions in patients receiving a preoperative $\beta$-blocker is not trivial and certainly does not contribute to quality surgical care.

Most surprisingly, the patients with preoperative $\beta$-blockade more commonly developed postoperative atrial fibrillation, a finding that has previously been noted in the literature. ${ }^{5}$ Although the pathophysiologic mechanism of this seemingly paradoxical finding is not well understood, some have conjectured that stopping administration of a $\beta$-blocker during the perioperative period prompts a rebound arrhythmogenicity within the myocardium. ${ }^{25}$ Another possible explanation is that these patients require greater inotropic support or receive more volume to treat hypotension following surgery. Both explanations could account for the development of postoperative atrial fibrillation in patients who receive a preoperative $\beta$-blocker.
Finally, this increase in postoperative atrial fibrillation can translate into greater resource use with higher hospitalization costs and longer lengths of stay, although only longer lengths of stay were significantly different between the matched cohorts in this study. ${ }^{26-28}$

Duration of ICU and hospital stays were longer in patients taking a preoperative $\beta$-blocker, although the difference in length of hospital stay was not clinically significant. Both of these metrics are gross estimations of a patient's postoperative course and can vary widely based on an individual's physiology and pathology, but they are also subject to logistical and systematic factors within the entire health care system. Nevertheless, longer lengths of stay lead to greater costs and demands on the entire health care system. Longer ICU stays and hospitalizations place patients at risk of developing postoperative complications, which clearly are not indications of high-quality surgical care and thus incongruent with the use of preoperative $\beta$-blocker administration as a quality metric. ${ }^{29}$

Clearly, this study has demonstrated some significant concerns with blanket administration of $\beta$-blockers to patients undergoing elective AVR. Other studiesparticularly in patients undergoing noncardiac surgeryhave revealed the complications that result when $\beta$-blockers are preemptively administered to patients in the preoperative setting when they have not previously been taking $\beta$-blockers. ${ }^{30,31}$ The most serious of these complications include increased rates of nonfatal strokes and death. ${ }^{31}$ Current recommendations advise against initiating $\beta$-blocker therapy before surgery. ${ }^{32}$ Despite these recommendations, there is some evidence that patients with a history of previous myocardial infarction derive significant benefit from preoperative $\beta$-blockade, thus highlighting the necessity of meticulous preoperative evaluation and preparation and thoughtful patient selection before surgery. ${ }^{33}$ In this study, approximately $8 \%$ of patients in the matched cohorts had a history of myocardial infarction, thus perhaps why this study did not demonstrate a significant benefit of preoperative $\beta$-blockade.

This study has some limitations that primarily stem from the fact that this was a retrospective analysis of registry data. In addition to possible selection bias, associations-and not causal relationships-can be identified. Moreover, the VCSQI registry is composed of de-identified STS data, which limits the granularity of the information that can be obtained. Salient details such as which $\beta$-blockers and dosages were used, timing or duration of $\beta$-blocker therapy, heart rate and blood pressure variation, technical intraoperative details, or postoperative vasopressor requirements cannot be determined from this data set. Although hospital and time were included in the propensity score model, institutional differences in postoperative critical care may remain confounders in these data. In addition, the propensity score used for risk 
adjustment can only account for measured covariates; thus, unmeasured covariates remain a confounding element within the data. Finally, this data registry only collects short-term follow-up and perioperative outcomes.

\section{CONCLUSIONS}

Preoperative $\beta$-blocker administration was not associated with improved outcomes after AVR but instead may increase postoperative complications and resource use, thus making preoperative $\beta$-blocker administration a poor metric with which to gauge surgical quality. As we struggle to define quality health care, we must be aware of the evidence that exists or does not exist to support standard practices. This study is evidence that blanket application of certain practices can lead to significant patient harm and increased resource use, neither of which are characteristics of quality health care. Although there are certainly patients for whom a preoperative $\beta$-blocker is advantageous and even necessary, we must be careful to not extrapolate the reported benefits from small non-randomized trials or retrospective studies. Given the significantly increased risks of postoperative cardiac arrest, renal failure necessitating hemodialysis, atrial fibrillation, transfusion, and longer duration of ICU stays, clinicians should evaluate each patient individually to determine whether not or a preoperative $\beta$-blocker should be administered.

\section{Webcast}

You can watch a Webcast of this AATS meeting presentation by going to: https://aats.blob.core.windows.net/media/17AM/ 2017-05-01/RM306/05-01-17_Room306_1701_Schubert. mp4.

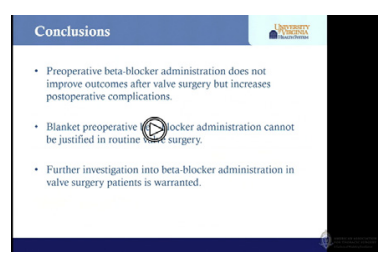

\section{Conflict of Interest Statement}

Dr Ailawadi has received unrelated personal fees from Edwards Lifesciences, Medtronic, Abbott, and Atricure. All other authors have nothing to disclose with regard to commercial support.

\section{References}

1. Poldermans D, Boersma E, Bax JJ, Thomson IR, van de Ven LL, Blankensteijn JD, et al. The effect of bisoprolol on perioperative mortality and myocardial infarction in high-risk patients undergoing vascular surgery. Dutch Echocardiographic Cardiac Risk Evaluation Applying Stress Echocardiography Study Group. N Engl J Med. 1999;341:1789-94.

2. Ferguson TB Jr, Coombs LP, Peterson ED, Society of Thoracic Surgeons National Adult Cardiac Surgery Database. Preoperative beta-blocker use and mortality and morbidity following CABG surgery in North America. JAMA 2002;287:2221-7.

3. Mangano DT, Layug EL, Wallace A, Tateo I. Effect of atenolol on mortality and cardiovascular morbidity after noncardiac surgery. Multicenter Study of Perioperative Ischemia Research Group. N Engl J Med. 1996;335:1713-20.

4. LaPar DJ, Crosby IK, Kron IL, Kern JA, Fonner E Jr, Rich JB, et al. Preoperative beta-blocker use should not be a quality metric for coronary artery bypass grafting. Ann Thorac Surg. 2013;96:1539-44.

5. Brinkman W, Herbert MA, O'Brien S, Filardo G, Prince S, Dewey T, et al. Preoperative beta-blocker use in coronary artery bypass grafting surgery: national database analysis. JAMA Intern Med. 2014;174:1320-7.

6. Brinkman WT, Herbert MA, Prince SL, Magee MJ, Dewey TM, Smith RL, et al. Preoperative beta-blocker usage: is it really worthy of being a quality indicator? Ann Thorac Surg. 2011;92:788-95.

7. Kohsaka S, Miyata H, Motomura N, Imanaka K, Fukuda K, Jyo S, et al. Effects of preoperative beta-blocker use on clinical outcomes after coronary artery bypass grafting: a report from the Japanese Cardiovascular Surgery Database. Anesthesiology. 2016;124:45-55.

8. Echahidi N, Pibarot P, O'Hara G, Mathieu P. Mechanisms, prevention, and treatment of atrial fibrillation after cardiac surgery. J Am Coll Cardiol. 2008; 51:793-801.

9. Society of Thoracic Surgeons. Quality performance measures-adult cardiac surgery. Available at: https://www.sts.org/quality-safety/performance-measures. Accessed February 17, 2019.

10. O'Brien SM, Shahian DM, DeLong ER, Normand SL, Edwards FH, Ferraris VA, et al. Quality measurement in adult cardiac surgery: part 2-Statistical considerations in composite measure scoring and provider rating. Ann Thorac Surg. 2007;83(4 Suppl):S13-26.

11. Shahian DM, Edwards FH, Ferraris VA, Haan CK, Rich JB, Normand SL, et al. Quality measurement in adult cardiac surgery: part 1-conceptual framework and measure selection. Ann Thorac Surg. 2007;83(4 Suppl):S3-12.

12. National Quality Forum. NQF-endorsed standards: preoperative beta blockade Vol 2017. Available at: http://www.qualityforum.org/Projects/s-z/Surgery_ Measures_2014/Final_Report.aspx. Accessed March 18, 2019.

13. D’Agostino RS, Jacobs JP, Badhwar V, Paone G, Rankin JS, Han JM, et al. The Society of Thoracic Surgeons Adult Cardiac Surgery Database: 2017 update on outcomes and quality. Ann Thorac Surg. 2017;103:18-24.

14. Society of Thoracic Surgeons Blood Conservation Guideline Task Force, Ferraris VA, Ferraris SP, Saha SP, Hessel EA II, Haan CK, Royston BD, et al. Perioperative blood transfusion and blood conservation in cardiac surgery: the Society of Thoracic Surgeons and The Society of Cardiovascular Anesthesiologists clinical practice guideline. Ann Thorac Surg. 2007;83(5 Suppl):S27-86.

15. Mathew JP, Fontes ML, Tudor IC, Ramsay J, Duke P, Mazer CD, et al A multicenter risk index for atrial fibrillation after cardiac surgery. JAMA. 2004;291:1720-9.

16. Shahian DM, O'Brien SM, Filardo G, Ferraris VA, Haan CK, Rich JB, et al. The Society of Thoracic Surgeons 2008 cardiac surgery risk models: part 1-coronary artery bypass grafting surgery. Ann Thorac Surg. 2009;88 (1 Suppl):S2-22.

17. Parsons L. Performing a 1:N case-control match on propensity score. Available at: https://support.sas.com/resources/papers/proceedings/proceedings/sugi29/165-29. pdf. Accessed February 17, 2019.

18. Orlowska-Baranowska E, Baranowski R, Hryniewiecki T. Incidence of syncope and cardiac arrest in patients with severe aortic stenosis. Pol Arch Med Wewn 2014;124:306-12.

19. Triposkiadis F, Karayannis G, Giamouzis G, Skoularigis J, Louridas G, Butler J. The sympathetic nervous system in heart failure physiology, pathophysiology, and clinical implications. J Am Coll Cardiol. 2009;54:1747-62.

20. Wang Y, Bellomo R. Cardiac surgery-associated acute kidney injury: risk factors, pathophysiology and treatment. Nat Rev Nephrol. 2017;13:697-711.

21. Floras JS. Sympathetic activation in human heart failure: diverse mechanisms, therapeutic opportunities. Acta Physiol Scand. 2003;177:391-8.

22. Floras JS. Sympathetic nervous system activation in human heart failure: clinical implications of an updated model. J Am Coll Cardiol. 2009;54:375-85.

23. Engoren MC, Habib RH, Zacharias A, Schwann TA, Riordan CJ, Durham SJ. Effect of blood transfusion on long-term survival after cardiac operation. Ann Thorac Surg. 2002;74:1180-6.

24. Paone G, Likosky DS, Brewer R, Theurer PF, Bell GF, Cogan CM, et al Transfusion of 1 and 2 units of red blood cells is associated with increased morbidity and mortality. Ann Thorac Surg. 2014;97:87-93; discussion 93-4. 
25. Choi EK, Shen MJ, Lin SF, Chen PS, Oh S. Effects of carvedilol on cardiac autonomic nerve activities during sinus rhythm and atrial fibrillation in ambulatory dogs. Europace. 2014;16:1083-91.

26. Aranki SF, Shaw DP, Adams DH, Rizzo RJ, Couper GS, VanderViliet M, et al. Predictors of atrial fibrillation after coronary artery surgery. Current trends and impact on hospital resources. Circulation. 1996:94:390-7.

27. Mathew JP, Parks R, Savino JS, Friedman AS, Koch C, Mangano DT, et al. Atrial fibrillation following coronary artery bypass graft surgery: predictors, outcomes, and resource utilization. MultiCenter Study of Perioperative Ischemia Research Group. JAMA. 1996;276:300-6.

28. Creswell LL, Schuessler RB, Rosenbloom M, Cox JL. Hazards of postoperative atrial arrhythmias. Ann Thorac Surg. 1993;56:539-49.

29. Lagoe RJ, Johnson PE, Murphy MP. Inpatient hospital complications and lengths of stay: a short report. BMC Res Notes. 2011;4:135

30. Group PS, Devereaux PJ, Yang H, Yusuf S, Guyatt G, Leslie K, et al. Effects of extended-release metoprolol succinate in patients undergoing non-cardiac surgery (POISE trial): a randomised controlled trial. Lancet. 2008;371:1839-47.

31. Bouri S, Shun-Shin MJ, Cole GD, Mayet J, Francis DP. Meta-analysis of secure randomised controlled trials of beta-blockade to prevent perioperative death in non-cardiac surgery. Heart. 2014;100:456-64.

32. Fleisher LA, Beckman JA, Brown KA, Calkins H, Chaikof EL, Fleischmann KE, et al. 2009 ACCF/AHA focused update on perioperative beta blockade incorporated into the ACC/AHA 2007 guidelines on perioperative cardiovascular evaluation and care for noncardiac surgery: a report of the American College of Cardiology Foundation/American Heart Association Task Force on Practice Guidelines. Circulation. 2009;120:e169-276.

33. Thaper A, Kulik A. Rationale for administering beta-blocker therapy to patients undergoing coronary artery bypass surgery: a systematic review. Expert Opin Drug Saf. 2018;17:805-13.

Key Words: perioperative management, aortic valve replacement, beta-blocker

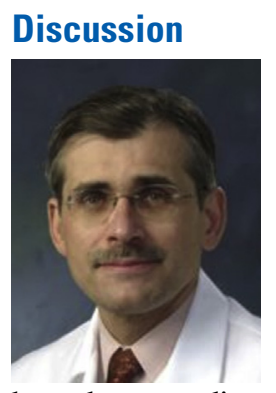

Dr Frank Baciewicz (Detroit, Mich). Dr Schubert, that was an excellent presentation and I congratulate you and the University of Virginia for looking into this issue.

As you point out, this issue of preoperative $\beta$-blockers has been looked at in a number of studies. There have been studies with perioperative $\beta$-blockers in patients who didn't undergo cardiac operations, and in fact that didn't improve their mortality and in fact they had a higher stroke rate. As you mentioned, in your Virginia study and other studies, there has been a question whether preoperative $\beta$-blockers improves outcomes in cardiac surgery and in fact whether it should be used as a value metric.

Given that background, my questions are the following. In your unmatched registry data of 17,000 patients who had valve surgery, there was no difference when you looked at the raw data on mortality; it was the same in $\beta$-blocker and no- $\beta$-blocker groups. And clearly, as you point out, the patients taking the $\beta$-blockers were higher risk on all preoperative characteristics, and before you propensity matched, the morbidity was also higher in almost every single measurement evaluated. So isn't taking $\beta$-blockers preoperatively just a surrogate for sicker patients? When you look at your propensity matched patients, is it possible that what you are really doing, because the mortality was the same, is that you are just looking at sicker patients so you would expect higher morbidities and that really what you are not looking at is other risk factors like did they come from a nursing facility or other frailty indices?

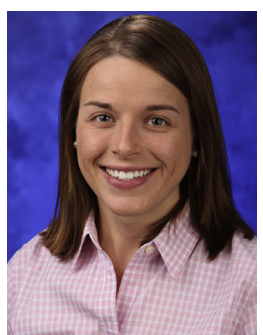

Dr Sarah Schubert (Charlottesville, $\mathrm{Va})$. There are certainly other frailty indices that go into this. We matched across a lot of those other variables, which should essentially of take them out of the equation. We were trying to distill this data down to figure out if the $\beta$-blockers are influencing these outcomes or not. There are certainly lots of other things that can go into this, and patients who are taking $\beta$-blockers before surgery may have more indices of frailty, as we would call them. Yet, our objective was trying to determine whether it is safe for these patients to be routinely started on a $\beta$-blocker medication immediately before going to valve surgery.

Dr Baciewicz. My next question is, did you drill down further on these patients? In other words, in these 5000 patients who were propensity matched, almost $50 \%$ of them had coronary disease, because you bypassed a high percentage of them, another percentage of them had experienced myocardial infarction beforehand, and about $6 \%$ or $7 \%$ had previous coronary artery bypass grafting; they were redo patients. So if you removed all those patients with coronary disease, which was about $50 \%$, did you look at the remaining group of patients and perhaps see what $\beta$-blockers did for those patients, whether it was either positive or negative? And in the same light, when you drilled down, did you look at patients with ejection fractions $<30 \%$ and could perhaps the $\beta$-blockers have made this patient group have really poor outcomes?

Dr Schubert. We did not do those subgroups analyses and they are definitely things that would be salient to look into.

Dr Baciewicz. I was really surprised by the atrial fibrillation rate being higher in the $\beta$-blockers patients. My question is multifaceted. If a patient got 1 dose of $\beta$-blocker before surgery like some of our coronary artery bypass graft patients do, did that count as a preoperative $\beta$-blocker? A lot of these patients probably don't get $\beta$-blockers after surgery because some of them are taking pressor agents and with some of those pressor agents being arrhythmogenic, do you have any of those data, because that might influence your outcome whether they have been taking $\beta$-blockers for a long time or whether they get this 1 dose so that we can check off the quality metric in the operating room.

Dr Schubert. Using the Society of Thoracic Surgeons data, we only know whether or not they were administered a $\beta$-blocker-essentially a yes or no checkbox-so we don't know how long they were taking a $\beta$-blocker before surgery. 
As for the question of atrial fibrillation developing after surgery, I have thought about this a lot because it seems a bit counterintuitive. Especially for those patients who were taking a $\beta$-blocker long term, withdrawing that $\beta$-blockade may make the heart a little bit more sensitivearrhythmogenic perhaps. There are some limited data out there that withdrawing a $\beta$-blockers can make the heart a bit more irritable after surgery, which may account for that.

The other reason that this could possibly come about is these patients are getting overfilled essentially after surgery. If they were taking a preoperative $\beta$-blocker they could have been more hypotensive on pump, leading to greater fluid resuscitation. As we are working to diurese them, they go into atrial fibrillation because their atrium is stretched.

Dr Baciewicz. Did most of these patients continue on $\beta$-blockers afterward or were most of them taking pressors afterward? Do you have any of those data?

Dr Schubert. I don't know that we have specific data on it. I know from our own institution most of these patients are taking at least 1 or 2 pressor agents for a day or 2 after surgery, if not a little bit longer.

Dr Baciewicz. Finally, did you look at hemoglobin levels before surgery, because in the Michigan cooperative, when we looked at transfusion rates, and preoperative hemoglobin level was a major factor influencing outcomes. I didn't see that among your preoperative characteristics.

Dr Schubert. Patients were matched on preoperative hematocrit level, not hemoglobin level, and there were no significant differences between the matched groups.

Dr Baciewicz. Are there any differences between the institutions in the state on this?

Dr Schubert. Obtaining approval to analyze the data of individual institutions within the Virginia Cardiac Services Quality Initiative can be a pretty involved process, and we did not pursue that specific analysis for this project.
Dr Baciewicz. Thank you very much.

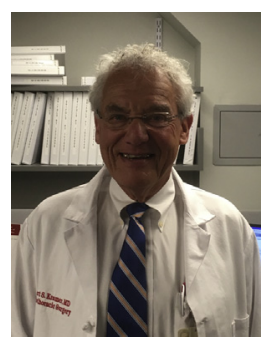

Dr Robert S. Kramer (Portland, Maine). I suspect you know how provocative this work is, so I will just distill it down to 1 thing. In 1 of the northern New England prediction models, we found that a preinduction heart rate $\leq 80 \mathrm{bpm}$ is a covariate. We have a standard of having our patients taking $\beta$-blockers preoperatively.

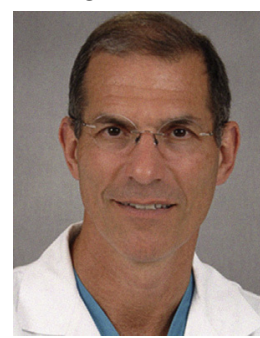

Dr Glen Whitman (Baltimore, $M d$ ). It is a covariate for what, Bob?

Dr Kramer. It is a covariate in a risk prediction model for coronary artery bypass graft surgery.

Dr Whitman. For mortality?

Dr Kramer. For mortality, yes.

Dr Schubert. That is how you include preoperative $\beta$-blockers use?

Dr Kramer. Yes, we use the preinduction heart rate as an indicator of adequate $\beta$-blockade. So my simple question to you is, were these patients taking $\beta$-blockers?

Dr Schubert. That is an excellent question. We do not because of the way that the Society of Thoracic Surgeons data are collected. $\beta$-Blocker use is only a yes or no checkbox and not correlated with heart rate.

Dr Whitman. It is a provocative article, and when one considers that in every instance the comorbidities of the population taking $\beta$-blockers were greater than those who weren't, there is a tremendous amount of pressure on you to propensity match them perfectly, because if you don't, $\beta$-blockers are going to get a bad reputation that they don't deserve as a result of a confounder that you are not taking into consideration. At this point, a definitive conclusion might be erroneous. 


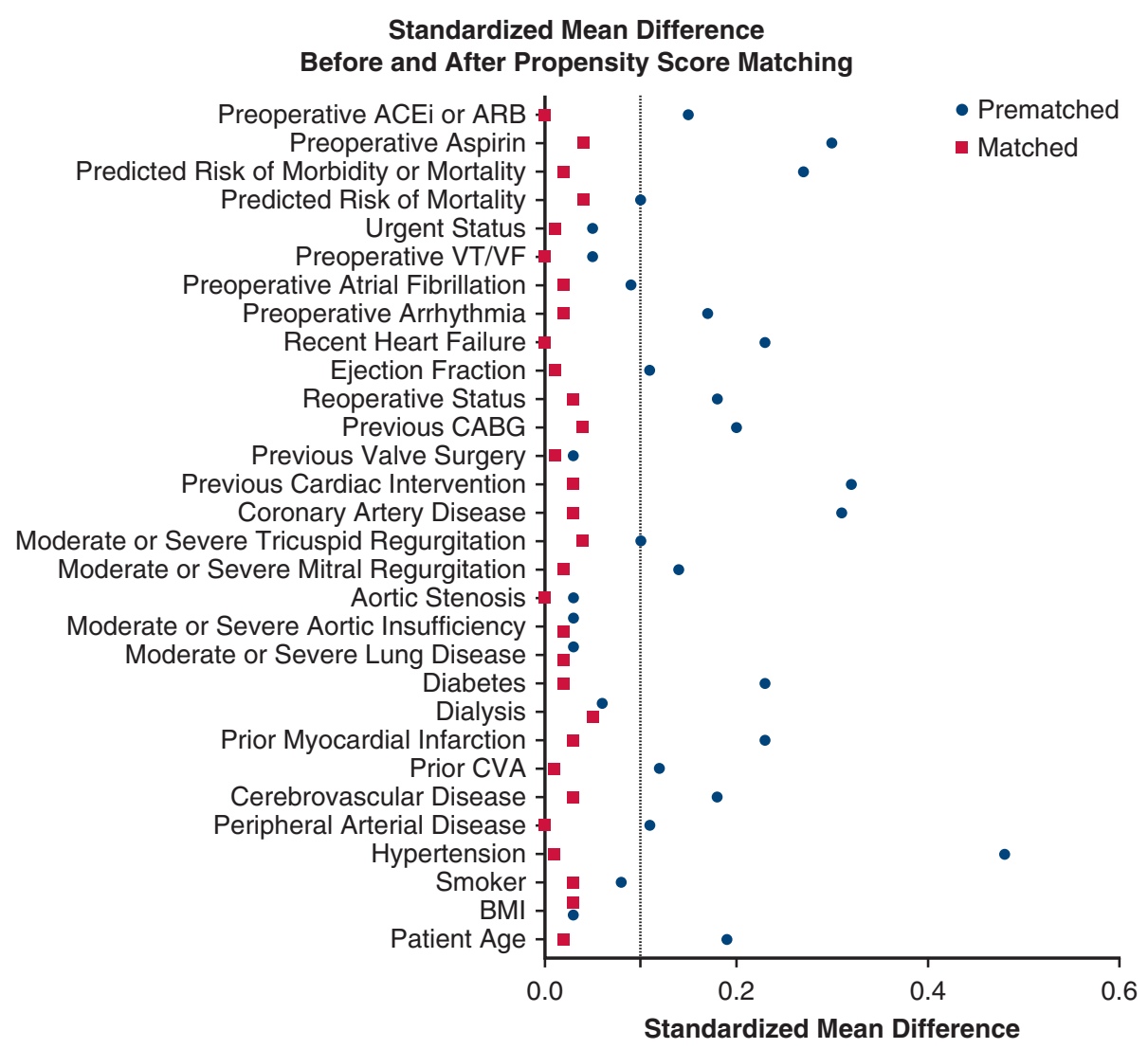

FIGURE E1. Balance assessment of baseline characteristics between the cohorts before and after 1:1 propensity matching. Blue boxes represent the standardized mean difference before matching, and red circles represent the standardized mean difference after matching. ACEi/ARB, Angiotensinconverting enzyme inhibitor/angiotensin receptor blocker; $V T / V F$, ventricular tachycardia/ventricular fibrillation; $C A B G$, coronary artery bypass grafting; $C V A$, cerebrovascular accident; $B M I$, body mass index. 
TABLE E1. List of covariates included in propensity score matching

Female sex

Patient age

Body surface area

Smoker

Diabetes

Last creatinine level

Dialysis

Chronic lung disease (none vs mild, moderate, or severe)

Peripheral arterial disease

Prior stroke

Heart failure within $2 \mathrm{wk}$

Hypertension

Prior myocardial infarction

Coronary artery disease

Ejection fraction

Aortic stenosis

Moderate/severe mitral regurgitation

Previous coronary artery bypass grafting

Previous valve

Previous cardiac intervention

Preoperative arrhythmia

Preoperative atrial fibrillation

Preoperative ventricular arrhythmia

Preoperative angiotensin-converting enzyme inhibitor/angiotensin receptor blocker

Preoperative aspirin

Preoperative steroids

Preoperative anticoagulation

Inotropic support

Urgent status

Active resuscitation

Shock

Annular enlargement

Year

Hospital (18 levels)

Society of Thoracic Surgeons predicted risk of mortality score 
TABLE E2. Characteristics of patient cohorts before matching

\begin{tabular}{|c|c|c|c|}
\hline Characteristic & Preoperative $\beta$-blocker $(n=3911)$ & No preoperative $\beta$-blocker $(n=3469)$ & $P$ value \\
\hline Age $(y)$ & $70(61,77)$ & $68(58,76)$ & $<.001$ \\
\hline Body mass index & $29.3(25.5,33.9)$ & $27.9(24.6,32.1)$ & $<.001$ \\
\hline Female & $1613(41.2)$ & $1406(40.5)$ & .540 \\
\hline Smoker & $1125(29.1)$ & $1129(32.9)$ & $<.001$ \\
\hline Hypertension & $3314(84.8)$ & $2241(64.6)$ & $<.001$ \\
\hline Diabetes & $1338(34.2)$ & $831(24.0)$ & $<.001$ \\
\hline Dialysis dependent renal failure & $86(2.2)$ & 49 (1.4) & .001 \\
\hline Peripheral arterial disease & $414(10.6)$ & $262(7.6)$ & $<.001$ \\
\hline Cerebrovascular disease & $667(17.1)$ & $380(11.0)$ & $<.001$ \\
\hline Prior cerebrovascular accident & $259(6.8)$ & $135(4.0)$ & $<.001$ \\
\hline Moderate or severe chronic lung disease & $406(10.5)$ & $330(9.6)$ & .200 \\
\hline Coronary artery disease & $1095(28.3)$ & $533(15.6)$ & $<.001$ \\
\hline Prior myocardial infarction & $512(13.2)$ & $218(6.3)$ & $<.001$ \\
\hline Heart failure within $2 \mathrm{wk}$ & $1826(46.8)$ & $1233(35.6)$ & $<.001$ \\
\hline LVEF $(\%)$ & $60(50,63)$ & $60(50,65)$ & $<.001$ \\
\hline Preoperative atrial fibrillation & $410(10.8)$ & $273(8.0)$ & $<.001$ \\
\hline Aortic insufficiency & $1080(27.7)$ & $1001(29.0)$ & .240 \\
\hline Aortic stenosis & $3450(88.7)$ & $3031(87.6)$ & .150 \\
\hline Mitral insufficiency & $436(12.4)$ & $245(7.8)$ & $<.001$ \\
\hline Mitral stenosis & $106(3.5)$ & $91(3.4)$ & .690 \\
\hline Tricuspid insufficiency & $224(6.8)$ & $137(4.5)$ & $<.001$ \\
\hline Previous cardiac intervention & 1238 (31.6) & $624(18.0)$ & $<.001$ \\
\hline Previous valve surgery & $227(5.8)$ & $180(5.2)$ & .249 \\
\hline Previous CABG & 465 (11.9) & $215(6.2)$ & $<.001$ \\
\hline Previous PCI & $514(44.8)$ & $150(28.9)$ & $<.001$ \\
\hline Reoperative status & $609(16.4)$ & $334(11.0)$ & $<.001$ \\
\hline STS PROMM (\%) & $15.8(11.4,22.0)$ & $12.9(9.5,18.5)$ & $<.001$ \\
\hline STS PROM $(\%)$ & $2.3(1.4,3.9)$ & $1.9(1.1,3.4)$ & $<.001$ \\
\hline \multicolumn{4}{|l|}{ Operative features } \\
\hline CPB time (min) & $105(86,130)$ & $101(84,125)$ & $<.001$ \\
\hline Crossclamp time (min) & $75(60,95)$ & $74(60,92)$ & .11 \\
\hline Annular enlargement & $202(5.6)$ & $126(4.4)$ & .04 \\
\hline
\end{tabular}

Values are presented as $\mathrm{n}(\%)$ or median (25th, 75 th percentile). $L V E F$, Left ventricular ejection fraction; $C A B G$, coronary artery bypass grafting; $P C I$, percutaneous coronary intervention; STS PROMM, Society of Thoracic Surgeons predicted risk of morbidity and mortality; STS PROM, Society of Thoracic Surgeons predicted risk of mortality; $C P B$, cardiopulmonary bypass. 